\title{
Sobre o domínio técnico: ensaio de crítica de alguns mitos do instrumentalizado mundo contemporâneo*
}

Prof. Dr. Dax Moraes

UERN

O presente trabalho deverá se deter em um dos aspectos da discussão heideggeriana a respeito da técnica, a saber, a pretensão do homem contemporâneo em utilizar-se da técnica como instrumento para solução dos problemas práticos do "mundo" tecnológico. Após um breve preâmbulo caracterizando o encobrimento do sentido da técnica, em que o mesmo se vela pelo ideal de progresso da razão, toma-se como ilustração o caso da suposta solução para o impacto humano na natureza do ponto de vista da questão ambiental. Por fim, reforçando a perspectiva do caráter não-utilitário do pensar, contraponto da afirmação heideggeriana de que a ciência não pensa, remete-se à caracterização aristotélica da filosofia primeira, em vista de se concluir este breve ensaio com a exigência de um pensar propriamente livre e sobre a liberdade em sentido próprio.

\section{PALAVRAS-CHAVE Técnica; Instrumento; Domínio; Asseguramento; Liberdade.}

This paper is dedicated to one of the aspects of Heideggerian discussion concerning technique, namely, contemporary man's purpose to use it as an instrument for solution of practical problems of the technological 'world'. After a brief introduction characterizing the meaning of technique as concealed by the ideal of rational progress, we take as an example the case of the supposed solution for human impact on Nature from the point of view of environmental questions. Finally, strengthening the not-utilitarian character of thinking as counterpoint of Heideggerian assertion that science does not think at all, we recur to Aristotle's characterization of prime Philosophy to conclude that urges to think properly free and about freedom in a proper sense.

KEY-WORDS Technique; Instrument; Domination; Assurance; Freedom. segundo Martin Heidegger" por ocasião da I Jornada Heidegger, realizada em Caicó-RN em 2009. 
Em diferentes conferências, ensaios e discursos como "Gelassenheit", Heidegger reitera sua preocupação com o destino do "mundo" técnico, atravessado pela compreensão tecnológica do ser, o que, para ele, consiste no grande perigo de nosso tempo. Esta compreensão de tal maneira se tornou mais e mais o lugar-comum em nossa cotidianidade apoiada em "metodologias", "gestões" e "mobilizações" que mal se consegue reconhecer aquilo para o que Heidegger precisamente já tanto buscava nos alertar: não é pela técnica que se soluciona os problemas decorrentes do "mundo" tecnológico.

Em sua conferência "A questão da técnica", Heidegger expõe o pressuposto básico dessa compreensão, que implica se tomar a técnica como mero instrumento, meio e, nesse sentido, como algo neutro, como estando a serviço dos fins projetados pela racionalidade humana. Desse modo, supõe-se que um aprimoramento da racionalidade (moral) conduzirá a um maior benefício no uso de técnicas.

É por isso que a concepção instrumental da técnica guia todo o esforço para colocar o homem num relacionamento direito com a técnica. Tudo depende de se manipular a técnica, enquanto meio e instrumento, da maneira devida. Pretende-se, como se costuma dizer, "manusear com espírito a técnica". Pretende-se dominar a técnica. Este querer dominar torna-se tanto mais urgente quanto mais a técnica ameaça escapar ao controle do homem. (HEIDEGGER, 2007a, p. 12).

No entanto, é já o "aprimoramento da racionalidade" uma possibilidade pertinente à compreensão tecnológica, de modo que não se a supera por esta via. Mas de que superação se trata aí? Não no sentido de uma recusa, mas superação de um modo de compreensão do "perigo".

A compreensão tecnológica supõe o "perigo" ora como resultado da técnica, uma perspectiva "retrógrada", ora, de uma perspectiva "progressista", como do mau-uso da técnica, ora mesmo como da falta de técnica - caso notório nos campos tão instrumentalizados da pedagogia e das políticas sociais. Encontramo-nos, neste último caso, em um novo "tecnicismo", cada vez mais inconsciente de si, sobretudo no âmbito da Educação e de sua própria "crítica ao tecnicismo" como um modo ultrapassado e autoritário, mas apenas no sentido de que a técnica não cumpra os objetivos almejados, para o que rapidamente se 
busca uma "correção". "Deve-se democratizar as técnicas", como se diz, isto é, universalizá-las, implementar seu plano totalizante na totalidade dos domínios de atividades. Vê-se no "domínio de novas tecnologias" por parte de cada sujeito a saída para os problemas da exclusão tecnológica (imposta pela própria técnica!) e consequente assujeitamento; a tecnologia torna-se "libertadora", meio para alargamento de possibilidades de inserção social e participação política ou ainda sua condição necessária. Parece mesmo havermos chegado ao limite do "desenraizamento"...

A concepção segundo a qual a origem do problema reside no "mau-uso" da técnica parece distinguir-se pouco disto, tendo em comum com o que acaba de ser dito a idéia de que a técnica possa ter um "bom-uso", um uso "crítico e consciente", mais "espiritual" ou "humano", um domínio "democratizado". A suposição de neutralidade (científica) do aparato técnico é tudo que endossa o aprisionamento e a dependência com relação a esta compreensão tecnológica e, ao mesmo tempo, sinaliza o desvio, cegos que ficamos para a essência da técnica (HEIDEGGER, 2007a, p. 11). Por outro lado, estimar a técnica como um mal em si parece evidentemente equivocado, na medida em que tal compreensão tecnológica, além de enraizar-se em nosso próprio modo de ser como ocupação (Besorgen), volta a desconsiderar que a técnica possa ser independente de nós, ou seja, dotada de uma essência e, por isso, não algo em si mesmo apenas a nosso serviço. Estimar a técnica como dependente de nós, como produto humano dentre outros, não apenas consiste em confundi-la com instrumentos e ferramentas, mas insistir na suposição de que se trata de um ente sob nosso controle como qualquer outro. Contrariamente ao que nos diz Heidegger já em Ser e tempo, isto faz supor que, em sua abertura à compreensão, os instrumentos já não se encontrassem dispostos segundo uma compreensão de mundo, a saber, uma compreensão técnica, profundamente enraizada em nosso modo de ser aí, de ser-no-mundo. Isto é, o mundo técnico é ele mesmo aberto originariamente segundo o modo de ser-no-mundo como decadência no impessoal.

Não está a nosso serviço e sob nosso poder a compreensão tecnológica. Não há poder, apenas vontade de poder, modernamente traduzível como vontade de conhecer. Somos nós a servi-la. Não podemos simplesmente dispensá-la de nosso serviço; os aparatos tecnológicos são hoje "indispensáveis":

Para todos nós os equipamentos, aparelhos e máquinas do mundo técnico são hoje imprescindíveis, para uns em maior e para outros em menor grau. Seria insensa- 
to investir às cegas contra o mundo técnico. Seria ter vistas curtas querer condenar o mundo técnico como uma obra do diabo. Estamos dependentes dos objetos técnicos que até nos desafiam a um sempre crescente aperfeiçoamento. Contudo, sem nos darmos conta, estamos de tal modo apegados aos objetos técnicos que nos tornamos seus escravos. (HEIDEGGER, [s.d.], p. 23)

Portanto, não se trata de atacar a técnica como se dela pudéssemos simplesmente, por escolha própria, nos livrar; pode-se mesmo reconhecer que não podemos sequer ignorá-la, nem o deveríamos. Contudo, atenção à técnica é atenção à sua essência, que reside na própria compreensão tecnológica que a faz emergir como tal, que lhe confere sentido. A atenção a esta essência é que pode abrir uma nova compreensão que dispense $a$ nós do serviço ao tecnológico.

Sendo insensato atacar ou dar as costas à técnica, também consiste em aprisionamento supor que a técnica esteja sob nosso controle como mero instrumento de racionalização de recursos.

[...] o projeto de Heidegger deveria nos alertar para o fato de que ele não está nos anunciando mais uma rebelião reacionária contra a tecnologia, apesar de muitos o tomarem como fazendo exatamente isto. Nem está ele fazendo o que pensadores progressistas gostariam de fazer: propondo um caminho para se ter a tecnologia sob controle para que então possa servir a nossos fins racionalmente escolhidos. [...] Assim, as preocupações [concerns] ontológicas de Heidegger são equivocadamente assimiladas a preocupações [worries] ecológicas acerca da devastação da natureza. (DREYFUS, 1993, p. 303)

Desse modo, se o interesse de Heidegger é o esquecimento do ser - um problema de ontologia -, torna-se secundária a "preocupação" empenhada junto ao ente "natureza" como tal, uma vez que importa antes o questionamento acerca do modo de ser de nossa cotidiana ocupação (Besorgen) com esse ente. No entanto, se uma perspectiva como a de Hans Jonas como que tendenciosamente esgarça o alerta de Heidegger, é um equívoco pensar que Heidegger 
despreze a "Natureza" quando, em verdade, se questiona, originariamente, o sentido conferido à Natureza pela compreensão tecnológica do ser. A compreensão tecnológica da natureza sempre encontra nela um objeto útil ao homem, seja no sentido de devastá-la pela obtenção de recursos, seja no de preservá-la em nome das gerações vindouras, onde se pode reconhecer uma insistência na concepção de "natureza" como objeto de que se extrai "recursos" para a vida humana (o que inclui alimentos, oxigênio, água ou mesmo prazer). Embora não fosse este último empenho algo disseminado no contexto em que Heidegger pensa o problema, trata-se evidentemente, em cada caso, de divergentes concepções racionalizantes e instrumentalizadoras do que se denomina ou se deve entender por "qualidade de vida": de um lado, o conforto, a eficiência e o dinamismo que nos proporciona o "mundo" tecnológico; de outro, uma "consciência ecológica" que enfatiza benefícios de longo-prazo em vista tão-somente de nossa "sobrevivência" como espécie dominadora. Hoje, como no tempo de Heidegger, vemo-nos presas da aceleração desenfreada e movidos por ocupações cada vez mais universalmente "interessantes"; cada vez mais o planeta deve se conduzir por um único "pensamento".

Em ambos os casos, reconhecemos a concepção de natureza como algo a ser posto à disposição. Sendo assim, não é pela mera inversão de pró a contra a tecnologia que escapamos à compreensão tecnológica. Se quer antes perpetuar nossa fuga à "responsabilidade ambiental" em vez de encará-la. Sendo impossível ignorá-la mediante a notória extinção de recursos, pelo que se deve racionalmente adiá-la tanto quanto possível. Enquanto isso, vê-se placas exortando à preservação do meio ambiente em estradas abertas por mineradoras que, em seu avanço, pagam pelo deslocamento de moradores locais. Por sua vez, deve-se antes compreender o modo de ser desta apropriação do ente "natureza", o qual se mostra através de dicotômicos "fins racionalmente escolhidos": o da extração - uso imediato voltado para o crescimento econômico e aprimoramento técnico - e o da conservação - uso que tem em vista a continuidade dos benefícios espontaneamente oferecidos por essa "natureza". Mas em que consiste tal inflamada oposição em sua possibilidade? Mudou o homem de posição? É correto dizer "sim!". Mas é isto um passo atrás? Para isto, a resposta é "não!". "A questão da objetividade, da possibilidade de oposição (a saber, do re-presentar que assegura e calcula) é a questão da possibilidade de conhecer" (HEIDEGGER, 2007c, p. 64). A troca de posições, possível apenas no âmbito das representações, nada tem a ver com o encaminhamento para um pensamento mais originário, meditativo, nada tem a ver com o "passo atrás". 
Esta passagem de um pensamento para outro [de um pensamento apenas representativo para um pensamento meditativo] não está, sem dúvida, apenas em simples troca de posição. Algo assim já não pode acontecer nunca porque as posições, junto com seus modos de troca, já estão presas ao pensamento representativo. O passo atrás abandona todo nível de um simples posicionar-se. (HEIDEGGER, 2007d, p. 159)

Isto certamente exige uma recolocação do problema da representação, embora não seja o objetivo do presente trabalho tematizá-lo, o que levaria a uma grande digressão. Fica claro, todavia, como a o-posição à exploração sempre insiste na logística do cálculo de benefícios, que apenas parecem menos imediatistas - acontece que, hoje, a urgência é evitar a extinção que bate às portas. A troca de posições é a eleição de um bem durável em detrimento de bens meramente provisórios que são produzidos às custas do primeiro. Ainda aí temos o "procedimento assegurador e processador" a que Heidegger se refere repetidas vezes, especialmente na década de 1950. Con-servar significa manter sob nosso serviço a totalidade do que nos serve; pre-servar significa disponibilizar o que já se encontra lá a nosso dispor. É evidente, neste caso, que a "consciência ecológica" é ainda uma racionalização de recursos na medida em que apela para a pre-servação e con-servação de certos bens valorados como superiores àqueles que são produzidos pelo homem em suas indústrias, não sendo casual que discursos como "a Amazônia é nossa" tenham lugar - o pronome possessivo indica também uma apropriação pública. O "público" como aquilo de compartilhado que não é devidamente cuidado por ninguém também mereceria atenção. Por isso, o modo de ser da apropriação instrumental em geral é um problema ontológico que precede a problemática sócio-geo-política. Desconsiderar isto é precisamente o "perigo" de que nos alerta Heidegger, pois a vitória dos preservacionistas ou conservacionistas, ao invés de nos libertar da compreensão tecnológica, não representa nada mais do que a vitória de uma visão de mundo tecnológica sobre outra. Trata-se do tipo de ideologia do progresso e do aprimoramento do espírito em que se calca a própria racionalidade técnica - tema tratado com mestria também por Adorno e Horkheimer em seu "Conceito de esclarecimento" -, o mesmo valendo para a opressora corrente "higienizadora" e "biométrica" que mais e mais acomete a cultura contemporânea, preenchendo-a com programas e políticas de saúde patologizando e excluindo os hábitos mais sedimentados sob o rótulo da longevidade e da qualidade de vida - problema este levantado por Foucault, décadas atrás, em grande parte de sua obra, sob a insígnia das "técnicas de si". 
O perigo, então, não é a destruição da natureza ou da cultura, mas certas espécies de práticas totalizantes um nivelamento de nossa compreensão do ser. Esta ameaça não é um problema para o qual devamos encontrar uma solução, mas uma condição ontológica que exige uma transformação de nossa compreensão do ser. (DREYFUS, 1993, p. 305)

O caráter "totalizante" que define a compreensão tecnológica apropriadora, segundo Dreyfus (1993, p. 306; grifo nosso), vincula-se ao niilismo na medida em que aponta para a ausência de propósito do homem contemporâneo:

Não temos fins específicos. O potencial movimento humano expressa perfeitamente esta compreensão tecnológica do ser, assim como o esforço de melhor organizar o futuro uso de nossos recursos naturais. Nós, assim, nos tornamos parte de um sistema que ninguém dirige, mas que se move rumo à total mobilização e aprimoramento de todos os entes, incluindo a nós. Eis por que Heidegger pensa que a sociedade perfeitamente planejada para o bem-estar de todos não é a solução para nossos problemas, mas a culminância da compreensão tecnológica do ser.

Pode-se sugerir que a superação do niilismo passe pelo reconhecimento da dignidade própria do ente enquanto tal, o que naturalmente não se deve confundir com uma atribuição de valor desde um ponto de vista ôntico, mas sim com um deixar-para-si o ente em si mesmo, em sua singularidade, o que se contrapõe à sua sujeição a práticas totalizantes que lhe são alheias e mero fruto da racionalização planificadora - "planificadora" no duplo sentido de "lançar planos" e "tornar planos". Por "dignidade" deve-se entender o oposto de "instrumentalidade", ou seja, aquilo cujo sentido, ou essência - para não se dizer erroneamente "valor" - reside em si, não em algo além, com um fim ao qual esse ente em questão sirva como simples meio. "Dignidade", portanto, significa a qualidade daquilo que é por si mesmo, e por isso deve ser deixado-para-si tal como é em si mesmo. Já "instrumentalidade" é o caráter daquilo que é em 
virtude do fim a que serve como meio. A diferença fundamental é que o sentido do instrumento não provém dele mesmo, mas é inteiramente dependente do que lhe é estranho, podendo ser por isso valorizado, desvalorizado, útil ou dispensável. Esta neutralização pela instrumentalização é justamente o que nega ao ente toda dignidade - p.ex., não importa verdadeiramente para devastadores ou ecologistas o que a natureza é, ou seja, sua essência, mas de que maneira lhes serve melhor, de que modo podem dela tirar maior proveito; importa-lhes como a natureza serve melhor à reprodução da vida humana, de modo que o que a natureza é, a essência da natureza, não é compreendido independente de sua utilidade prática e das práticas humanas junto à natureza, mas tão-somente a partir de sistemas de valor. É segundo uma reorganização das representações de valor, não de sua ruptura, que se dão as trocas de posição. Se a própria reorganização é ditada, como interpretação de mundo, pela compreensão técnica, a totalidade dos entes é reduzida à instrumentalidade ainda que fins particulares sejam redefinidos. O caráter instrumental da "Natureza" é então mantido e daí o ente recebe seu valor. Similar é o que se dá com relação à própria técnica:

Pois estabelecer fins, procurar e usar os meios para alcançá-los é uma atividade humana. Pertence à técnica a produção e o uso de ferramentas, aparelhos e máquinas, como a ela pertencem estes produtos e utensílios em si mesmos e as necessidades a que eles servem. O conjunto de tudo isto é a técnica. A própria técnica é também um instrumento [Einrichtung], em latim instrumentum. (HEIDEGGER, 2007a, p. 11-12)

A natureza é um dos objetos apropriados pela técnica. Uma vez apropriada pela compreensão técnica, sua essência é de tal modo esquecida a ponto de perder até mesmo o caráter de objeto, convertendo-se ela mesma em instrumento, e não apenas nossas práticas apropriativas/disponibilizadoras da natureza. "No sentido da dis-ponibilidade (Bestand), o que é [steht] já não está para nós em frente e defronte, como um objeto [Gegenstand]" (HEIDEGGER, 2007a, p. 21). "Bestand", talvez mais claramente traduzível por "capital", stricto sensu, remete a "Beständigkeit", constância, estabilidade, ou seja, "aquilo que está lá" à nossa disposição, para nosso uso segundo os fins traçados em atendimento a nossas necessidades, como que "à nossa espera", nosso fundo, agora converti- 
do em fundamento de todas as formas de vida, vida esta que não é propriamente a "nossa", mas ao mesmo tempo de todos e ninguém. Por isso, o ente como que desaparece mesmo enquanto objeto, na exata medida em que, por si mesmo, é coisa alguma. Não é à toa que, alhures, também diz Heidegger, por exemplo: "A Natureza transforma-se num único posto de abastecimento gigantesco, numa fonte de energia para a técnica e indústria modernas" ([s.d.], p. 19). Ademais, a tradução por "capital" permite perceber o quanto de significado econômico adquire a dis-ponibilidade, pois em qualquer empresa, independente de seu porte, $o$ capital é precisamente aquilo de que não se pode lançar-mão sob risco de falência; o capital assegura todos os empenhos e tarefas, mas ele mesmo não pode ser esgotado, deve antes ser mantido e aumentado, re-produzido ininterruptamente.

A lógica do capital disponível totaliza a interpretação da natureza como fonte de recursos de modo a incluir o próprio homem, reduzido à sua naturalidade e não à mera animalidade, sempre na ordem dos materiais. Heidegger (2007c, p. 82-83) já prevê:

Como o homem é a matéria-prima mais importante, pode-se contar que, em virtude da pesquisa química contemporânea, algum dia fábricas haverão de ser construídas para a produção artificial de material humano. [...] O abuso de toda matéria-prima, inclusive da matéria-prima "homem", para beneficiar a produção técnica da possibilidade incondicionada de tudo fabricar determina-se, veladamente, pelo completo vazio em que o ente, a matéria do real, se acha inserido. Esse vazio deve ser preenchido. [...] A técnica é, nesse sentido, a organização da falta porque, contra o seu saber, refere-se ao vazio do ser.

É neste sentido que os fins do mundo técnico não convergem em finalidade alguma e se inserem no contexto do niilismo. Ainda para além do que prevê Heidegger nessa passagem, entificando e naturalizando até mesmo as disposições existenciais, uma vez convertidas em "sentimentos" e ora em processos neuroquímicos, a moda das neurociências valida e investe na pretensão de controlarmos até mesmo o amor, que, segundo notícia divulgada em junho de 2009, poderia ser produzido artificialmente pela introdução, no cérebro, de um hormônio chamado ocitocina, de acordo com as pesquisas de Larry Young e sua equipe na Universidade de Emory, Atlanta, Estados Unidos. É notável - e isto, sim, paradoxal - que o homem reconheça na possibilidade de controle 
sobre a totalidade dos entes a libertação da natureza, mito que necessariamente depende do pressuposto de que todas as coisas sejam entes determinados mecanicamente, causalmente, naturalmente, de que todos os comportamentos humanos sigam processos naturais e, portanto, sejam eles mesmos nada mais do que entes e meios para seus fins. Nisto encontramos um exemplo de como nos deixamos escravizar por aquilo que supostamente liberta, equivocadamente interpretado como aquilo de que dispomos "livremente", que se encontra sob nosso suposto poder de gerar em nós mesmos, exterminando para isso todo mistério - o amor mesmo deixa de ser um mistério; é a ação da ocitocina sobre o cérebro, conforme prova o experimento com ratos (!). O amor é reduzido ao impulso sexual a fim de ser assim passível de controle pela ciência que então pode torná-lo disponível. Com que fim? Salvar casamentos? Tornar a humanidade feliz? Não - tornar previsível, como todo necessário deve ser; tornar necessário, como todo previsível deve ser.

A ciência põe o real. E o dis-põe a pro-por-se num conjunto de operações e processamentos, isto é, numa sequência de causas aduzidas que se podem prever. Desta maneira, o real pode ser previsível e tornar-se perseguido em suas consequências. É como se assegura o real em sua objetidade. Desta decorrem domínios de objetos que o tratamento científico pode, então, processar à vontade. (HEIDEGGER, 2007b, p. 48)

Mas é importante notar que a oposição aqui estabelecida entre "dignidade" e "instrumentalidade" não significa uma defesa da exclusividade da "dignidade" e supressão das práticas instrumentais. Afinal, como foi dito, pertence a nosso modo de ser - e isto consiste em um diagnóstico, não é um dogma fatalista ou conformista - a apropriação dos entes e, ademais, cuidado é requerido com a própria noção de "dignidade", cujo significado ontológico e amoral acima indicado de modo algum pode ser subsumido a qualquer princípio ou ordem de valor. Pelo contrário, "valor" também já sempre pressupõe escalas, méritos, fins etc. Valores são, pelo contrário, atribuídos àquilo que, já apropriado pela representação, convertido em reserva e disponibilizado ao uso já se encontra destituído que qualquer valor intrínseco, valendo apenas em virtude de outra coisa. No entanto, o perigo reside na desatenção à essencial dignidade daquilo que é por-si e, enquanto tal, deve ser deixado-para-si. Trata-se, em resumo, do "sim e não" à técnica, que nada 
tem de paradoxal, tampouco de hesitação, mas indica a utilização meditada dos instrumentos, o que, por sua vez, difere do que se convencionou chamar "uso consciente, uso sustentável", sendo a esta altura bastante claro em que medita "consciência" e "sustentabilidade" são noções suspeitas.

Podemos utilizar os objetos técnicos e, no entanto, ao utilizá-los normalmente, permanecer ao mesmo tempo livres deles, de tal modo que os possamos a qualquer momento largar. Podemos utilizar os objetos técnicos tal como eles têm de ser utilizados. Mas podemos, simultaneamente, deixar esses objetos repousar em si mesmos como algo que não interessa àquilo que temos de mais íntimo e de mais próprio. Podemos dizer "sim" à utilização inevitável dos objetos técnicos e podemos ao mesmo tempo dizer "não", impedindo que nos absorvam e, desse modo, verguem, confundam e, por fim, esgotem nossa natureza [Wesen]. (HEIDEGGER, [s.d.], p. 24)

Em conformidade ao que foi dito antes, podemos ainda - e este é o perigo - passar de meros objetos da técnica (que cotidianamente nos permitimos ser, por exemplo, enquanto tomados como público-alvo, mercado consumidor etc.) a uma privação ou total esquecimento do ser, o que significa, como a natureza, tornarmo-nos não mais algo como "consumidores finais", mas sim, meios para os fins tecnológicos. Isto é fácil não apenas de se prever, mas de constatar, na medida em que nossas vontades se veem orientadas e finalmente conduzidas por fins totalizantes. Nosso "poder de escolha" deixa de ser o alvo, neste exemplo, para ser ele mesmo aniquilado pela impessoalidade da instrumentalização. Por isso, diz Heidegger (2007a, p. 35), é necessário que nos demos conta do que é essencial na técnica em vez cairmos pura e simplesmente no fascínio pelas coisas técnicas, uma vez que, enquanto tomarmos a técnica como instrumento, nos manteremos na vontade de dela nos apoderarmos, passando, assim, à margem de sua essência.

Encontramo-nos, então, em meio à contra-dignidade instrumental, sobre o que ainda parece restar algo a pontuar no que concerne mais propriamente ao pensar e à liberdade que o caracteriza. Já Aristóteles reconhecia como atividade própria daquele que é livre aquela cujo fim não residisse alhures, além, mas na própria atividade. Isto mesmo significava o caráter não-útil da ciência das primeiras causas, ordinariamente denominada metafísica. 
[...] é lógico que, tendo sido descobertas numerosas artes [technôn], umas voltadas para as necessidades da vida e outras para o bem- estar, sempre tenham sido julgados mais sábios os descobridores destas do que os daquelas, porque seus conhecimentos não eram dirigidos ao útil. Daí resulta que, quando já se tinham constituído todas as artes desse tipo [i.e. saberes técnicos e produtivos], passou-se à descoberta das ciências que visam nem ao prazer nem às necessidades da vida, e isso ocorreu primeiramente nos lugares em que primeiro os homens se libertaram de ocupações práticas [próton escholasan, começaram a ter ócio]. [...] Consideramos ainda, entre as ciências, que seja em maior grau sapiência a que é escolhida por si e unicamente em vista do saber, em contraste com a que é escolhida em vista do que dela deriva. [...] De modo que, se os homens filosofaram para libertar-se da ignorância, é evidente que buscavam o conhecimento unicamente em vista do saber e não por alguma utilidade prática. E o modo como as coisas se desenvolveram o demonstra: quando já se possuía praticamente tudo o de que se necessitava para a vida e também para o conforto e para o bem-estar, então se começou a buscar essa forma de conhecimento. É evidente, portanto, que não a buscamos por nenhuma vantagem que lhe seja estranha; e, mais ainda, é evidente que, como chamamos livre o homem que é fim para si mesmo e não está submetido a outros, assim só esta ciência, dentre todas as outras, é chamada livre, pois só ela é fim para si mesma. (ARISTÓTELES, 2002, p. 6/7/9/11/13 ${ }^{1}$ )

Vê-se o desvio tomado, na interpretação técnica, pela tese de que a felicidade pertence ao sábio, passando pelo dogma moderno de que "saber é poder". Esse caráter não-útil - i.e., não-instrumental - da ciência cujo fim se encontra nela mesma, ou, em outras palavras, o saber pelo saber, não se deve entender negativamente como o inútil, ou seja, aquilo que está às antípodas de toda utilidade. É notório que a Filosofia, embora utilizável para os mais variados fins, tem sua dignidade no fato de não constituir um corpo de saber a ser buscado em vista da solução de problemas, desimpedindo o caminho do homem para suas

1981 b 17-23; 982 a 14-16; 982 b 19-28. 
realizações como seria o caso de qualquer saber instrumental. Isto não evita que a Filosofia seja buscada em nome de tais finalidades, utilitariamente, como, por exemplo, requisito para a formação de jovens para a cidadania. Esta é, sim, uma de suas possibilidades, remontando mesmo à pedagogia platônica, o que não significa, porém, que resida aí sua dignidade, ou mesmo que sua dignidade possa surgir ou ser mantida nesses termos. Pelo contrário: devemos pensar que é justamente por deter a dignidade de um saber buscado não utilitariamente, mas por si mesmo, que a Filosofia pode ter como possibilidade formar jovens para o que quer que seja - isto, sim, representa melhor a perspectiva pedagógica de Platão. Qualquer debate acerca do papel - leia-se utilidade - de uma filosofia ou seu ensino deve ter em conta sua motivação mais essencial. Contudo, e aí reside a diferença, tal possibilidade só se mantém na medida em que deixemos a Filosofia entregue a si mesma, como pensamento livre de e por homens livres, um diálogo sem fim e sem fins.

Um diálogo sem fim não é falta. É sinal do ilimitado que resguarda, em si e para o pensamento, a possibilidade de uma transformação de destino.

Quem, no entanto, só espera do pensar um asseguramento, e calcula o dia em que o pensamento possa ser preterido e deixado de lado, esse só é capaz de exigir do pensamento autoaniquilamento. (HEIDEGGER, 2007e, p. 226)

É, portanto, da liberdade, que nada tem a ver com livre-arbítrio, que deve surgir o pensar, não o inverso. Do mesmo modo, não cabe à Filosofia a produção de certezas senão às custas da destruição de todo filosofar e, com ele, de toda liberdade. Seria dizer que não será a sabedoria a nos libertar, tanto menos qualquer técnica, mas, ao contrário, que da liberação deve proceder toda verdadeira sabedoria; cabe-nos pensar o sentido do "ser-livre" antes de nos entregarmos a qualquer promessa de saberes libertadores, mesmo por que tal coisa não se dá senão nos mitos modernos.

Por fim, para que a Filosofia não pareça restar como única alternativa - mesmo porque parece estar longe de sê-lo como, aliás, sempre esteve -, encerremos com as palavras de Dreyfus (1993, p. 310) acerca do "poder salvador das coisas insignificantes" e a prática do não-útil: 
Heidegger mantém que devemos aprender a apreciar práticas marginais - o que Heidegger denomina o poder salvador das coisas insignificantes -, práticas tais como amizade, viajar como mochileiro por regiões desabitadas, beber o vinho local com amigos. Todas estas práticas permanecem marginais precisamente porque resistem à eficiência. Estas práticas podem também, certamente, estar comprometidas [engaged in] com a saúde e uma maior eficiência. Na verdade, o maior perigo é que mesmo as práticas marginais sejam mobilizadas como recursos. Eis por que razão devemos proteger estas práticas comprometidas [endangered].

Tais práticas, portanto, para escaparem da compreensão técnica do ser, não devem receber nossa adesão como "soluções" para o stress, para o tédio ou como mero "revigorante" para o corpo ou para o espírito, como diversão, como distração, como alheamento... Já alertara Heidegger (2007a, p. 20): “[...] o Reno continua, de fato, sendo o rio da paisagem. Pode ser. Mas de que maneira? - À maneira de um objeto dis-posto à visitação turística por uma agência de viagens, por sua vez, dis-posta por uma indústria de férias". Não caberia aqui, por sua vez, discutir o uso feito da recreação e a ordenação do ócio por organizações em vista da produtividade e em nome, por exemplo, da "melhoria da qualidade de vida no trabalho" etc., ou mesmo da cultura higiênica implementada pela moda já aludida acima. Basta que se reflita sobre em que medida já não consiste isso em uma ameaça às práticas marginais, uma apropriação das mesmas pela compreensão tecnológica e sua perspectiva totalitariamente planificadora...

ARISTÓTELES. Metafisica. Vol. II: Texto grego com tradução ao lado. Trad. para o italiano por Giovanni Reale; Trad. Marcelo Perine. Edição bilíngue grego/ português. São Paulo: Loyola, 2002.

DREYFUS, H. L. Heidegger on the connection between nihilism, art, technology, and politics. In: GUIGNON, C. B. (Ed.). The Cambridge companion to Heidegger. Cambridge: Cambridge University Press, 1993. p. 289-316. HEIDEGGER, M. Serenidade. Trad. Maria Madalena
Andrade e Olga Santos. Lisboa: Instituto Piaget, [s.d.]. (Coleção Pensamento e Filosofia). Inclui “Para discussão da serenidade - de uma conversa sobre o pensamento, que teve lugar num caminho de campo".

HEIDEGGER, M. A questão da técnica. Trad. Emmanuel Carneiro Leão. In: HEIDEGGER, M. Ensaios e conferências. 4. ed. Petrópolis: Vozes; Bragança Paulista: Edusf, 2007a. p. 11-38. 
HEIDEGGER, M. Ciência e pensamento do sentido.

Trad. Emmanuel Carneiro Leão. In: HEIDEGGER, M. Ensaios e conferências. 4. ed. Petrópolis: Vozes; Bragança Paulista: Edusf, 2007b. p. 39-60.

HEIDEGGER, M. A superação da metafisica. Trad. Marcia Sá Cavalcante Schuback. In: HEIDEGGER, M. Ensaios e conferências. 4. ed. Petrópolis: Vozes; Bragança Paulista: Edusf, 2007c. p. 61-86.

HEIDEGGER, M. A coisa. Trad. Emmanuel Carneiro Leão. Acrescido do posfácio "Carta a um jovem estudante”, de 18/06/1950. Trad. Marcia Sá Cavalcante Schuback. In: HEIDEGGER, M. Ensaios e conferências. 4. ed. Petrópolis: Vozes; Bragança Paulista: Edusf, 2007d. p. 143-164.

HEIDEGGER, M. Moira (Parmênides, fragmento VIII, 34-41). Trad. Marcia Sá Cavalcante Schuback. In: HEIDEGGER, M. Ensaios e conferências. 4. ed. Petrópolis: Vozes; Bragança Paulista: Edusf, 2007e. p. 205-226.

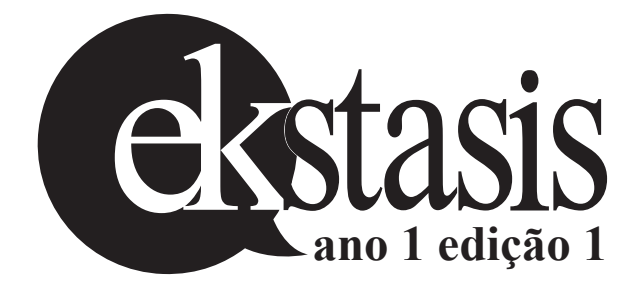

